NOTA CRÍTICA 



\title{
La medicalización de las madres como distorsión mecanicista de los comienzos de la vida humana
}

\author{
The medicalization of mothers as a mechanistic distortion of the \\ beginnings of human life
}

JESÚS GARCÍA BLANCA*

\begin{abstract}
Resumen: Como parte central de la medicalización de la vida humana en todos sus aspectos, analizo brevemente la medicalización de las madres, que provoca una distorsión de los procesos vitales en los comienzos de la vida: concepción, embarazo, parto y crianza. Partimos de la hipótesis de que el proceso de medicalización se realiza desde un modelo médico mecanicista que se apoya en una lectura reduccionista de la ciencia moderna, así los efectos que provoca son necesariamente mecanicistas y suponen una distorsión con efectos de poder y con graves consecuencias para la salud de las madres y sus criaturas.

Palabras clave: medicalización, mecanicismo, salud, nacimiento, crianza.
\end{abstract}

\begin{abstract}
As a central part of the medicalization of human life in all its aspects, I briefly analyze the medicalization of mothers that causes a distortion of the vital processes in the beginning of life: conception, pregnancy, childbirth and breeding. Since the process of medicalization is carried out from a reductionist and mechanistic medical model that is based on a reductionist reading of modern science, the effects it causes are necessarily mechanistic and involve a distortion with power effects and with serious consequences for the health of Mothers and their creatures.
\end{abstract}

Keywords: medicalization, mecanicism, health, childbirth, breeding.

\section{El modelo médico hegemónico es mecanicista}

El modelo médico que domina los sistemas sanitarios, las instituciones y el imaginario popular en la mayor parte del mundo tiene su origen en el siglo XVIII, cuando la ciencia comienza a sustituir a la religión y aparece la autoridad médica, que pone en marcha un ritual para curar las dolencias clasificándolas y definiéndolas como "enfermedades". Como parte de ese proceso, la iglesia es sustituida por el hospital como dispositivo de control y

Recibido: 20/08/2017. Aceptado: 09/10/2017.

* Autor de El rapto de Higea. Mecanismos de poder en el terreno de la salud y la enfermedad (Virus, 2010); La Sanidad contra la Salud (iEdiciones, 2015); Vacunas: una reflexión crítica (iEdiciones, 2016) en co-autoría con el Dr. Enric Costa, y Wilhelm Reich, inspirador de rebeldía (Cauac, 2017). e-mail: keffet@gmail.com 
normalización, primero de los propios médicos y luego de los enfermos ${ }^{1}$. Durante el siglo XIX, el pensamiento mecanicista surgido de la Ilustración ${ }^{2}$ y la gestación de la industria farmacéutica, facilitan el triunfo de la Teoría Microbiana, hito clave del modelo hegemónico, que inicia la guerra contra las bacterias mediante el empleo masivo de antibióticos y vacunas, una guerra que cien años después se demostrará autodestructiva ${ }^{3}$. La Teoría Microbiana facilita el proceso de industrialización de la medicina en varios sentidos: sustitución del tratamiento de enfermos por el tratamiento de enfermedades mediante diagnósticos progresivamente más tecnologizados y la fabricación en serie de "remedios" farmacológicos que consiguen aparentar eficacia haciendo creer que la curación consiste en suprimir síntomas y esconder su toxicidad atribuyendo sus efectos a nuevos microbios.

El Modelo Médico Hegemónico se consolida durante el siglo XX, favorecido por la reconversión de las multinacionales farmacéuticas, especialmente tras la Segunda Guerra Mundial, transformándose en una poderosa herramienta de poder que controla la formación, la información, la investigación y los servicios sanitarios progresivamente dominados por la súper especialización y la tecnología. Actualmente, el Modelo Médico Hegemónico mantiene una amplia credibilidad e influencia debido, no a razones científicas sino sociopolíticas: son los enormes intereses de poder académicos, políticos y económicos los que mantienen vigentes los dogmas de un modelo que no solamente ha fracasado a la hora de resolver la mayor parte de las patologías crónicas y degenerativas, sino que ha causado muchas de ellas y empeorado otras.

Este modelo se apoya en un enfoque reduccionista y mecanicista de la ciencia -que comienza con las propuestas de $\mathrm{Comte}^{4}$, se alimenta de autores positivistas en lo filosófico ${ }^{5}$ y mecanicistas en lo biológico ${ }^{6}$, y llega a su paroxismo con la genética determinista ${ }^{7}-$. Como modelo es reduccionista en su mirada, ya que se limita de modo generalizado a lo puramente corporal, podríamos decir a lo físico-químico, a poder ser con criterios cuantitativos, mecanicista en sus fundamentos teóricos e "industrial" en su ejercicio práctico. El enfoque mencionado caracteriza sobre todo las zonas más cercanas al poder, constituyendo las posiciones oficiales que muchas veces se presentan como las de una "comunidad científica" que no existe como tal y que en realidad responde a un reducido grupo de científicos investidos de poder académico, que a cambio ofrecen legitimidad a los poderes políticos y económicos que posibilitan sus privilegios.

1 Foucault, M. (1963) Naissance de la clinique. Une archéologie du regard médical. [El nacimiento de la clínica, una arqueología de la mirada médica, Siglo XXI, Buenos Aires, 2008.] Foucault, M. (1973) La verdad y las formas jurídicas. Barcelona, Gedisa, 2017.

2 A partir de los trabajos de numerosos investigadores, como William Harvey (1578-1657), Thomas Willis (16211675), William Croone (1633-1684), uno de los primeros fellows de la recién creada Royal Society británica, Robert Hooke (1635-1703)... todos ellos figuras clave en el desarrollo de las especialidades que configuran la visión atomizada de la medicina: anatomía, fisiología, neurología, etc.

3 Sandín, M. (2010) La guerra contra bacterias y virus: una lucha autodestructiva. A debate, volumen 3, número 117 , enero-febrero.

4 Comte, A. (1852) Catéchisme positiviste, ou Sommaire exposition de la religión universelle, en onze entretiens systématiques entre une femme et un prêtre de l'humanité. [Catecismo positivista. Madrid, Editorial Nacional, 1952]

5 John Stuart Mill, Herbert Spencer, empirocriticismo, neopositivismo.

6 Rudolf Virchow, Charles Darwin, neodarwinismo, biología molecular.

7 George Mendel, Watson y Crick, Proyecto Genoma Humano, biotecnología. 
Así, esa ciencia oficial desprecia lo cualitativo para quedarse con lo medible y contable, un desprecio por lo esencial cuyo origen se halla en el racionalismo cartesiano, que a su vez hunde sus raíces en el Renacimiento y ha desembocado en el materialismo moderno. Paradójicamente fue un movimiento humanista el que sentó las bases de la deshumanización ${ }^{8}$ : para servir a la máquina, el hombre mismo se ha convertido en máquina que contempla a los seres vivos y al universo como máquinas, lo que nos conduce a otra paradoja: la ciencia de la vida estudia lo no vivo, la biología -la oficial- dice estudiar máquinas ${ }^{9}$ que pueblan una civilización cada vez más reducida a lo material que ha roto su conexión vertical con lo trascendente, e incluso su conexión horizontal con el ecosistema.

\section{La medicalización como distorsión de procesos vitales}

La medicalización de las madres, es decir, la intromisión del Modelo Médico Hegemónico y sus instituciones en el ciclo vital natural concepción-embarazo-parto-lactanciacrianza, supone una distorsión mecanicista que pone en peligro el papel biológico que desempeñan las mujeres y que en última instancia se traduce en una agresión contra la vida. El Modelo Médico Hegemónico se ha convertido en la institución más importante de control social dentro de la sociedad contemporánea ${ }^{10}$ y sus protocolos de actuación en una agresión permanente a la salud de las mujeres que, en los países pobres se concreta en programas de esterilización y experimentación de fármacos violando las normativas legales y la ética médica, y en los países ricos en intervenciones médicas y tecnológicas que alteran procesos naturales en todo el arco vital de la mujer y se convierten en una amenaza para la vida.

Un documento elaborado durante la presidencia de Richard Nixon y recientemente desclasificado ${ }^{11}$, expresa con crudeza la concreción de efectos de poder contra la mujer en el llamado "tercer mundo": "la despoblación debería ser la más alta prioridad de la política de Estados Unidos hacia el tercer mundo". El informe recomendaba políticas de control de la natalidad en los países en los que el crecimiento de la población ponía en peligro la obtención de materias primas para la industria estadounidense, políticas que llevan décadas en ejecución con la colaboración de las Naciones Unidas, la UNICEF, la OMS, el Fondo de Población de las Naciones Unidas o la Federación Internacional de Planificación Familiar. El documento añade: los gobiernos del tercer mundo que no se sometan voluntariamente al programa de reducción de población deberán ser forzados a esa sumisión por estos medios: denegarles el crédito por parte del FMI, incitar a la rebelión a la población hambrienta, etc.

8 Sabato, E. (1951) Hombres y engranajes, Madrid, Alianza Editorial.

9 "Somos máquinas de supervivencia, vehículos robóticos ciegamente programados para preservar las moléculas egoístas conocidas como genes”. Dawkins, R. (1976) The selfish gene. [El gen egoista. Grupo Anaya Comercial, 2000].

10 De Miguel, J. M. (1990) Salud y poder. Madrid, Siglo XXI Editores.

11 National Security Study Memorandum 200 (NSSM 200) - April 1974 (http://www.population-security.org/28APP2.html). 


\section{Patrones de normalidad}

En cambio, en los países ricos, el Modelo Médico Hegemónico opera fundamentalmente mediante "patrones de normalidad" que ha ido estableciendo en todos los ámbitos, desde el peso que corresponde a tal edad de un bebé hasta la regularidad con la que debe presentarse una menstruación, de modo que todo lo que se desvíe de esos patrones se considera por definición "alteraciones", las cuales automáticamente suponen "necesidad de atención médica" con el fin de restablecer la "normalidad". Se perpetra pues un proceso mecanicista que consiste en corregir la naturaleza, forzándola para que los elementos naturales se ajusten a los parámetros artificiales produciendo una distorsión que compromete la salud y en el caso de las madres, la gestación de la nueva vida. Ese "ajuste" a los patrones de normalidad se lleva a cabo habitualmente mediante el uso de fármacos o, en caso "necesario" mediante intervenciones quirúrgicas. Con lo que se producen dos agresiones: la distorsión misma del proceso natural y los daños causados por los fármacos o la cirugía, identificados eufemísticamente como "efectos secundarios" o "indeseados".

En lo que respecta a la fertilidad, se han desarrollado fármacos para inducir la ovulación y otros para inhibirla; reguladores del ciclo hormonal -como el Progyluton- que puede producir hemorragias vaginales, flujos anormales, dismenorrea y síndrome premenstrual, es decir, los trastornos que pretende corregir, anticonceptivos para tratar alteraciones menstruales, fármacos que inciden en distintos puntos del ciclo hormonal, antiinflamatorios, sensibilizadores de la insulina, estrógenos, etc., muchas veces administrados durante toda la vida fértil de la mujer provocando dolores, trastornos nerviosos, depresión, alteraciones cardiovasculares o distorsiones de la sexualidad.

El recurso quirúrgico en este caso, las histerectomías o extirpaciones de útero han llegado a extremos alarmantes: un estudio referido a 35 hospitales de Los Ángeles arroja las siguientes cifras: 6284 extirpaciones; 5557 realizadas sin establecer previamente su necesidad; tras las intervenciones, el 30\% de ellas -mujeres de entre 20 y 29 años- estaban completamente sanas $^{12}$. Según la Agency for Healthcare Research and Quality, del Departamento de Salud de los Estados Unidos, la histerectomía es la segunda operación más frecuente en mujeres estadounidenses tras la cesárea. Un estudio realizado por la Universidad de California concluía que el $70 \%$ de las histerectomías son inapropiadas ${ }^{13}$. Paralelamente, está el frente de una batalla químico-tecnológica contra la infertilidad: en los años cuarenta del siglo XX la media de espermatozoides por mililitro de semen en un adulto de mediana edad era de 250 millones, en los noventa descendió a 40 millones y en 1999 la OMS estableció un mínimo "normal" de 20 millones, cifra que redujo en 2010 a 15 millones $^{14}$.

Las tres técnicas básicas de reproducción asistida -inducción de la ovulación mediante hormonas, inseminación artificial y fecundación in vitro- tienen un alto coste, no únicamente económico: síndrome de hiperestimulación ovárico, jaquecas, ansiedad, insomnio y depresión, entre otros efectos "indeseados" que se suman a la paradoja final: la infertilidad

12 Landaburu, E. (2000) Cuídate, Compa. Tafalla, Txalaparta.

13 Broder, M.S., Kanouse, D.E., Mittman, B.S., Bernstein, S.J. (2000) The appropriateness of recommendations for hysterectomy. Obstet Gynecol. 2000 Feb; 95(2): 199-205. (https://www.ncbi.nlm.nih.gov/pubmed/10674580).

14 Parámetros de Calidad Seminal según la Organización Mundial de la Salud (OMS). (https://www.institutobernabeu.com/foro/2012/09/07/calidad-seminal-segun-la-organizacion-mundial-de-la-salud-oms/) 
de los descendientes. Solo en España se practican cada año 56000 tratamientos, fruto de los cuales nacen unos nueve mil niños ${ }^{15}$. Durante el embarazo se acumulan las intromisiones del estamento médico: la conocida Talidomida, fabricada por Chemie Grünenthal en Alemania, se comercializó en 1958 para “combatir" los vómitos habituales en las primeras semanas o meses de embarazo. Una vez más, un fármaco de cuyos efectos dan cuenta más de 20000 bebés mutilados ${ }^{16}$, se utiliza para distorsionar un proceso natural necesario: la limpieza que el cuerpo hace para recibir a la criatura en su seno. Menos conocido, el Dietilestilbestrol es un estrógeno sintético que se receta durante el embarazo para prevenir abortos y que fue retirado en 1978 -aunque prohibido desde 1971- debido a los centenares de casos de cáncer de vagina que produjo en las hijas de quienes lo habían tomado ${ }^{17}$.

A estos y otros fármacos debemos añadir los problemas generados por la práctica rutinaria de ecografías: una recopilación de cincuenta estudios realizados en China in utero demuestran el riesgo extremo de los ultrasonidos: en casos leves pueden producirse desordenes de la personalidad y TDAH, en los peores casos enfermedades oftalmológicas, malformaciones, alergias, ictericia, restricción del crecimiento intrauterino, trastornos del espectro autista $u$ otras formas de daños neurológicos graves ${ }^{18}$.

\section{El bebé es un mamífero}

El parto es el momento de mayor acumulación de distorsiones, comenzando por el hecho de ser tratado en espacios físicos y condiciones similares a los de una intervención quirúrgica. El inicio de la medicalización del parto podemos situarlo a comienzos del siglo XX, cuando Joseph DeLee elaboró una serie de tratados de obstetricia en los que recomendaba el uso sistemático de fórceps y episiotomía, así como la administración de sedantes y éter o cloroformo a la parturienta junto con derivados de trigo para acelerar la salida de la placenta ${ }^{19}$. Contra todas las evidencias que ponen de manifiesto la inutilidad y peligrosidad de inducciones mediante administración de oxitocina sintética, monitorización, episiotomías, cesáreas, cortes prematuros del cordón umbilical, separación de madre y bebé, estas agresiones a veces brutales se siguen practicando de modo rutinario incluso desoyendo recomendaciones de la OMS y violando derechos de consentimiento informado.

La lactancia en la primera hora de nacimiento puede prevenir el $22 \%$ de las muertes neonatales ${ }^{20}$. Tanto la OMS como la UNICEF, como documentos y declaraciones internacionales recomiendan estimular la lactancia materna lo antes posible y prolongarla a demanda del bebé. Ello es debido a que la lactancia no es únicamente una cuestión de

15 El País, 20 de agosto de 2011.

16 Los afectados de la talidomida se quedan sin indemnizaciones. ECSalud, 22 de octubre de 2014 (http://consalud. es/empresas/empresas-con-salud/-los-afectados-de-la-talidomida-se-quedan-sin-sus-indemnizaciones-13961).

17 Dietilestilbestrol, el primer producto hormonal catalogado en 1971 como cancerígeno humano. El País, 4 de enero de 1981 (https://elpais.com/diario/1981/01/04/sociedad/347410805_850215.html).

18 West, J. (2015) 50 Human Studies, in Utero, Conducted in Modern China indicate extreme risk for Prenatal Ultrasound: A new Bibliography. Nueva York, Edición Autor.

19 Leavitt, J. W. (1988) Joseph B. DeLee and the Practice of Preventive Obstetrics. American Journal of Public Health, 1988, Vol. 78, No. 10.

20 Edmon, K. M. et al. (2006) Delayed breastfeeding initiation increases risk of neonatal mortality. Pediatrics, marzo 2006. Vol. 117, No. 3 (http://pediatrics.aappublications.org/content/117/3/e380.short). 
alimentación. El mamífero humano nace sin haber completado su desarrollo, y debería considerársele un feto al menos durante el primer año de vida fuera del útero ${ }^{21}$. Desde esa perspectiva la leche materna constituye un fluido de conexión entre la madre y el bebé, un segundo cordón umbilical que garantiza la nutrición y al mismo tiempo asegura un desarrollo saludable de los sistemas durante -al menos- los dos primeros años de vida.

Toda intervención, que tenga como consecuencia la interrupción de la lactancia natural provocará la distorsión de procesos naturales cruciales para la salud y la vida: la producción de leche en las cantidades y composición adecuada a cada momento del día y a lo largo del crecimiento, mecanismos de regulación mutua de la temperatura, hormonas, factores de crecimiento, células madre para emergencias, linfocitos T para uso a largo plazo, compuestos anti-inflamatorios y factores neurotróficos necesarios para la maduración del sistema nervioso y del neuronal, elementos para la maduración y puesta a punto de las relaciones de simbiosis con microorganismos: células, enzimas, citoquinas, probióticos y multitud de especies bacterianas que se suman a los adquiridos en la placenta y durante el parto ${ }^{22}$.

La crianza es un territorio compartido entre los dispositivos de poder sanitarios y educativos: se superponen, se solapan, incluso actúan de modo sinérgico produciendo efectos devastadores, alterando lo que uno de los primeros científicos en estudiar al niño sano denominó "autorregulación" 23 con consecuencias suficientemente estudiadas ${ }^{24}$ : la fabricación de ciudadanos normalizados, emocionalmente castrados, predispuestos a la sumisión ${ }^{25}$. Las raíces de la indolencia, de la aceptación acrítica de las imposiciones del poder, del egoísmo, de la competitividad y yendo más lejos, de la violencia, de la crueldad, de la perversidad y de la deshumanización imperantes se encuentran pues en la distorsión de los inicios, en la agresión estructural a las criaturas.

Consecuentemente, para evitar problemas de salud y neutralizar o debilitar los efectos de poder debemos, desde lo individual y desde lo social, recuperar, impulsar y proteger la maternidad entrañable ${ }^{26}$ y la capacidad de autorregulación de los procesos naturales, y por otro lado reducir las intervenciones médicas al mínimo indispensable en todos los ámbitos, pero especialmente en los que afectan a los comienzos de la vida.

21 Portman, A. (1942) Die Biologie und das neue menschenbild. Citado por Carballo, R. (1952) Cerebro interno y mundo emocional. Barcelona, Labor.

22 Jakatis, B. M. Denning, P. W. (2014) Human Breast Milk and the Gastrointestinal Innate Immune System. Clinical Perinatology, 2014, 41 (2): 423-435 (https://www.ncbi.nlm.nih.gov/pmc/articles/PMC4414019/). Rodríguez, J. M. (2014) The origin of human milk bacteria: is there a bacterial entero-mammary pathway during late pregnancy and lactation. Advances in Nutrition, Nov, 2014. Vol. 5: 779-784. Aagaard, K. et al. (2014) "The placenta harbors a unique microbiome". Science Translational Medicine, 21 May 2014: Vol. 6, Issue 237, pp. 237ra65. Funkhouser, L. J. Y Bordenstein, S. R. "Mom Knows Best: The Universality of Maternal Microbial Transmisión”. PLoS Biol 11(8): e1001631: (http://journals.plos.org/plosbiology/article?id=10.1371/journal. pbio.1001631). Cabrera-Rubio, R. et al. (2012) "The human milk microbiome changes over lactation and is shaped by maternal weight and mode of delivery”. Am J Clin Nutr September 2012 vol. 96 no. 3 544-551. (http://ajcn.nutrition.org/content/96/3/544.full).

23 Reich, W. (1951) Children of the Future [Farrar, Strauss \& Giroux, 1985].

24 Wilhelm Reich, Frederic Leboyer, Konrad Stettbacher, Michael Balint, James Prescott, Michel Odent, Nils Bergman, Casilda Rodrigañez, Xavier Serrano.

25 Rodrigañez, C. (1996) La represión del deseo materno y la génesis del estado de sumisión inconsciente, Murcia, Cauac Editorial Nativa, 2008.

26 Blázquez García, M. J. (2006) Maternidad entrañable y gozosa. Zaragoza, Prensas de la Universidad de Zaragoza. 


\section{Referencias}

Aagaard, K. et al. (2014): "The placenta harbors a unique microbiome". Science Translational Medicine, 21 May 2014: Vol. 6, Issue 237, pp. 237ra65.

Blázquez García, M. J. (2006): Maternidad entrañable y gozosa. Zaragoza, Prensas de la Universidad de Zaragoza.

Broder, M.S., Kanouse, D.E., Mittman, B.S., Bernstein, S.J. (2000): The appropriateness of recommendations for hysterectomy. Obstet Gynecol. 2000 Feb; 95(2):199-205 (https:// www.ncbi.nlm.nih.gov/pubmed/10674580).

Cabrera-Rubio, R. et al. (2012): "The human milk microbiome changes over lactation and is shaped by maternal weight and mode of delivery". Am J Clin Nutr September 2012 vol. 96 no. 3 544-551. (http://ajcn.nutrition.org/content/96/3/544.full).

Comte, A. (1852): Catéchisme positiviste, ou Sommaire exposition de la religión universelle, en onze entretiens systématiques entre une femme et un prêtre de l'humanité.

Dawkins, R. (1976): The selfish gene. [El gen egoista. Grupo Anaya Comercial, 2000].

De Miguel, J. M. (1990): Salud y poder. Madrid, Siglo XXI Editores.

Edmon, K. M. et al. (2006): Delayed breastfeeding initiation increases risk of neonatal mortality. Pediatrics, marzo 2006. Vol. 117, No. 3 (http://pediatrics.aappublications.org/ content/117/3/e380.short).

Foucault, M. (1963): Naissance de la clinique. Une archéologie du regard médical. [El nacimiento de la clínica, una arqueología de la mirada médica, Siglo XXI, Buenos Aires, 2008].

Funkhouser, L. J. y Bordenstein, S. R. "Mom Knows Best: The Universality of Maternal Microbial Transmisión”. PLoS Biol 11(8): e1001631: (http://journals.plos.org/plosbiology/article?id=10.1371/journal.pbio.1001631).

Jakatis, B. M. Denning, P. W. (2014): Human Breast Milk and the Gastrointestinal Innate Immune System. Clinical Perinatology, 2014, 41 (2): 423-435 (https://www.ncbi.nlm. nih.gov/pmc/articles/PMC4414019/).

Landaburu, E. (2000) Cuídate, Compa. Tafalla, Txalaparta.

Leavitt, J. W. (1988): Joseph B. DeLee and the Practice of Preventive Obstetrics. American Journal of Public Health, 1988, Vol. 78, No. 10.

Portman, A. (1942): Die Biologie und das neue menschenbild. Bern, Univ. Bern.

Reich, W. (1951): Children of the Future [Farrar, Strauss \& Giroux, 1985].

Rodrigañez, C. (1996): La represión del deseo materno y la génesis del estado de sumisión inconsciente [Murcia, Cauac Editorial Nativa, 2008].

Rodríguez, J. M. (2014): The origin of human milk bacteria: is there a bacterial enteromammary pathway during late pregnancy and lactation. Advances in Nutrition, Nov, 2014. Vol. 5: 779-784.

Sandín, M. (2010): La guerra contra bacterias y virus: una lucha autodestructiva. A debate, volumen 3 , número 117 , enero-febrero.

Sabato, E. (1951): Hombres y engranajes, Madrid, Alianza Editorial.

West, J. (2015): 50 Human Studies, in Utero, Conducted in Modern China indicate extreme risk for Prenatal Ultrasound: A new Bibliography. 
